\title{
Antitumoral effect of a nonviral interleukin-2 gene therapy is enhanced by combination with 5-fluorouracil
}

\author{
Jeffrey S. Bishop, Nikolyn M. Thull, Majed Matar, Abraham Quezada, William E. Munger, \\ Tara L. Batten, Susanne Muller, and Federica Pericle
}

Valentis, Inc., The Woodlands, Texas 77381.

\begin{abstract}
Using a novel cationic lipid delivery system consisting of $N$-[1-(2,3-dioleoyloxy)propyl]- $N, N, N$-trimethylammonium chloride and cholesterol, we delivered murine interleukin-2 (IL-2) cDNA directly into an established murine renal cell carcinoma (Renca). Production of IL-2 within the tumor induced rejection of established tumors (62\% on average), whereas control plasmid had little or no effect ( $17 \%$ on average). Surviving animals treated with IL-2:lipid were highly resistant to Renca rechallenge, but not to cross-challenge with a syngeneic mammary adenocarcinoma. Experiments on selectively immunosuppressed animals indicated a requirement for $\mathrm{CD}^{+} \mathrm{T}$, natural killer, and polymorphonuclear cells. By contrast, depletion of CD4 ${ }^{+} \mathrm{T}$ cells did not disrupt the ability of IL-2:lipid to induce tumor rejection. A combination of IL-2 gene therapy with 5-fluorouracil treatment increased the antitumoral efficacy and survival of mice bearing primary and metastatic Renca tumors (42\% survival with IL-2:lipid compared with 94\% survival with IL-2:lipid plus 5-fluorouracil). These data indicate that rejection of primary and metastatic tumors can be achieved after intratumoral delivery of a nonviral IL-2 gene therapy, and is increased in combination with systemic delivery of a conventional chemotherapeutic agent. Cancer Gene Therapy (2000) 7, 1165-1171
\end{abstract}

Key words: Interleukin-2; gene therapy; chemotherapy; 5-fluorouracil; immunotherapy; cancer.

$\mathrm{C}$ ytokine gene therapy is under intensive preclinical and clinical study to ultimately provide efficacious alternatives to current chemotherapeutic regimens in patients. Interleukin-2 (IL-2), a T-cell growth factor that enhances both nonspecific immune responses, such as activation of macrophages, natural killer (NK) cells, and lymphokine-activated killer cells, as well as major histocompatibility complex-restricted cytotoxic T-cell responses, has been studied extensively. Recombinant IL-2 (rIL-2) is the currently recommended immunotherapeutic agent for human renal cell carcinoma (RCC) by the US Food and Drug Administration. ${ }^{1}$ IL-2 protein, however, has a short half-life in sera and requires repeated doses for antitumoral effects. This cytokine exhibits limited efficacy against certain cancers and has a number of well-documented toxic effects when given systemically, such as capillary leak syndrome, hypotension, arrhythmia, nausea, fever, vomiting, and liver and kidney damage. $^{2-4}$ The deleterious effects of systemic administration of cytokines coupled with the cloning of cytokine genes have prompted research into the local expression of cytokines.

Implantation with ex vivo IL-2 gene-transfected tumor cells $^{5,6}$ or fibroblasts ${ }^{7,8}$ in experimental animal models

Received October 1, 1999; accepted April 15, 2000.

Address correspondence and reprint requests to Dr. Federica Pericle, Valentis, Inc., 8301 New Trails Drive, The Woodlands, TX 77381-4248. E-mail address: pericf@Valentis.com has been shown to be effective in delaying tumor growth and causing tumor rejection. A number of ex vivo gene therapy strategies have gone into clinical trials, mainly in RCC and melanoma. ${ }^{9}$ However, ex vivo approaches are costly, time-consuming, and labor-intensive because they involve excision of tumor tissue, establishment of a cell culture, transduction of the cells in culture, selection and growth of the transduced cells, and reimplantation of the cells into the animal model or patient. Such drawbacks led to the development of methods for direct transfection/transduction of tumor cells in vivo. Previously, DNA encoding IL-2 has been used in direct administration gene therapy models using adenoviral, ${ }^{10,11}$ particle-mediated gene-gun ${ }^{12,13}$ and lipid-mediated delivery. ${ }^{14,15}$

We have employed a gene therapy approach using a murine IL-2 (mIL-2)-expressing plasmid complexed with $N$-[1-(2,3-dioleoyloxy)propyl]- $N, N, N$-trimethylammonium chloride (DOTMA):cholesterol (lipid) to deliver functional IL-2 cDNA by direct injection into established tumors. The specific objective of our study was to evaluate the antitumoral response induced by IL-2:lipid and to examine the effectiveness of combining IL-2 gene therapy with a conventional chemotherapeutic agent, 5-fluorouracil (5-FU). 5-FU is currently widely used clinically for the chemotherapy of a variety of tumors, including gastric, colon, stomach, and breast carcinomas. An active metabolite of 5-FU, 5-fluoro-2'-deoxyuridine$5 '$-monophosphate, inhibits thymidylate synthetase, decreasing the formation of thymidylate needed for DNA synthesis. 
By employing direct lipid-mediated gene transfer into established tumors, we demonstrated that the production of IL-2 within the tumor induces a strong antitumoral immune response and tumor-specific memory. The antitumoral activity induced by IL-2:lipid was efficacious against primary tumors and prevented the formation of lung metastases. Lastly, we present evidence that IL-2 gene therapy can be used in combination with a conventional chemotherapeutic agent to enhance the antitumoral activity against primary and metastatic tumors.

\section{MATERIALS AND METHODS}

\section{Animals}

Female BALB/c mice ( $6-8$ weeks old, $\sim 25 \mathrm{~g}$ body weight) were obtained from Charles River Laboratories (Raleigh, NC). Mice were provided with rodent feed and water ad libitum and kept at $23^{\circ} \mathrm{C}, 40-70 \%$ humidity, and a 12 -hour/12-hour lightdark cycle. Animals were allowed an acclimation period of at least 4 days before the start of a study. Animal management conformed to an approved Institutional Animal Care and Use Committee protocol.

\section{Tumors}

Renca, a spontaneously arising murine RCC, was generously provided by Dr. Drew M. Pardoll (John Hopkins Hospital, Baltimore, Md). TS/A, a spontaneously arising moderately differentiated murine mammary adenocarcinoma, ${ }^{16}$ was generously provided by Dr. Guido Forni (University of Turin, Turin, Italy). Tumor cell cultures were maintained in sterile disposable flasks at $37^{\circ} \mathrm{C}$ in a humidified $5 \% \mathrm{CO}_{2}$ atmosphere using RPMI 1640 medium supplemented with $12.5 \%$ fetal bovine sera, $100 \mathrm{U} / \mathrm{mL}$ penicillin-G, $100 \mu \mathrm{g} / \mathrm{mL}$ streptomycin sulfate, and $2 \mathrm{mM}$ L-glutamine (all from Life Technologies, Gaithersburg, Md).

\section{Plasmid formulations}

Plasmids were propagated in Escherichia coli strain DH5 $\alpha$ and purified using alkaline lysis and column chromatography. Two plasmids were used in these studies, pIL0555A and pVC0612. pIL0555A (IL-2) is a pUC ori-based plasmid of 3452 bp coding for mIL-2 cDNA $;{ }^{17}$ this plasmid contains the cytomegalovirus promoter, cytomegalovirus $5^{\prime}$ untranslated region, and a bovine growth hormone 3 ' polyadenylation signal and site. Plasmid pVC0612 (empty plasmid (EP)), which is a 2940-bp plasmid identical with pIL0555 except that it lacks the IL-2 cDNA sequence, was used as a control for nonspecific effects. Plasmid preparations were tested for endotoxin contamination by a Limulus amebocyte lysate assay (BioWhittaker, Walkersville, Md). A single lot of pIL0555 with an endotoxin level of 6 international units of endotoxin per milligram of DNA was used for all experiments. Multiple lots of EP were used in these studies with an average endotoxin content of 10 international units per milligram of DNA.

Small unilamellar vesicles of a 1:1 molar ratio of DOTMA (Avanti Polar Lipids, Alabaster, Ala) and cholesterol (Avanti Polar Lipids) were prepared by microfluidization. Plasmidlipid formulations were prepared by mixing purified plasmids with these liposomes under controlled conditions in a solution containing $10 \%$ lactose as an isotonic agent. The final DOTMA:cholesterol formulation had a DNA:lipid charge ratio of $1: 0.5(-/+)$.

\section{Cytokine enzyme-linked immunosorbent assays (ELISAs)}

To measure IL-2 production in tumors, female BALB/c mice were implanted with $7 \times 10^{5}$ Renca cells in a $30-\mu \mathrm{L}$ volume subcutaneously (s.c.) in the left flank on day 0 . On day 10 , animals bearing tumors of $20-25 \mathrm{~mm}^{3}$ elliptical volume were randomized into groups of six and injected intratumorally (i.t.) with $6 \mu \mathrm{g}$ of IL-2:lipid or EP:lipid. Tumors were harvested 24 hours after treatment, placed individually into the wells of 24-well tissue culture plates (Becton-Dickinson Labware, Lincoln Park, NJ), and cut into 10-12 pieces. Conditioned culture medium was collected after 24 hours of culture at $37^{\circ} \mathrm{C} / 5 \%$ $\mathrm{CO}_{2}$, centrifuged, and stored at $-70^{\circ} \mathrm{C}$ until assayed for cytokines. The conditioned medium was assayed for the presence of the IL-2 gene product and a secondary cytokine, interferon- $\gamma$ (IFN- $\gamma$ ), using commercial ELISA kits (mIL-2, R\&D Systems, Minneapolis, Minn; murine IFN- $\gamma$, Genzyme, Cambridge, Mass) according to the manufacturer's instructions.

\section{In vivo studies}

Female BALB/c mice were challenged s.c. with $7 \times 10^{5}$ Renca cells in the middle of the left flank. Treatments with EP:lipid or IL-2:lipid began 6 or 7 days later when the tumor size reached $\sim 10 \mathrm{~mm}^{3}$; treatments were repeated at 3- to 4-day intervals for 2 weeks (two treatments per week). Groups of untreated tumor-bearing animals were included as controls. Tumor volume was measured with electronic calipers to determine two perpendicular diameters and depth. Measurements of the tumor masses were performed twice a week for 40-50 days. All mice bearing tumor masses of $>1 \mathrm{~cm}^{3}$ volume or showing signs of severe ulceration of tumors or moribundity were sacrificed for humane reasons.

In rechallenge and cross-challenge experiments, animals that rejected the initial Renca tumor challenge were rechallenged with a higher inoculum of Renca cells $\left(1 \times 10^{6}\right.$ cells $/ 30$ $\mu \mathrm{L}$ ) in the opposite (right) flank from the initial challenge. A group of naive animals was also challenged as a control for tumor-take. In the cross-challenge experiment, animals that rejected both the initial Renca challenge and the Renca rechallenge, as well as a naive group, were implanted with $2 \times$ $10^{5} \mathrm{TS} / \mathrm{A}$ cells also in the right flank. Animals were monitored for tumor establishment.

Antibody $(\mathrm{Ab})$ depletions of $\mathrm{CD}^{+}, \mathrm{CD} 8^{+}, \mathrm{NK}$, or polymorphonuclear (PMN) cells were done on days 6 and 13 after tumor implant. Tumors were treated twice per week for 2 weeks with IL-2:lipid or EP:lipid ( $6 \mu \mathrm{g} /$ mouse) starting on day 7 after tumor challenge. $\mathrm{CD} 4^{+}$and $\mathrm{CD} 8^{+} \mathrm{T}$ cells were depleted using $500 \mu \mathrm{L}$ of a 1/10 dilution of ascites fluid from GK1.5 (207-TIB) and 2.43 (210-TIB) hybridomas, respectively. (Hybridomas were obtained from American Type Culture Collection, Manassas, Va; ascites fluid was obtained from Charles River Laboratories.) NK cells were depleted using 50 $\mu \mathrm{L} /$ mouse of rabbit anti-mouse asialo-GM1 (Wako, Richmond, Va). PMN cells were depleted using $100 \mu \mathrm{g} /$ mouse of Ab RB6-8C5 (PharMingen, San Diego, Calif). Abs were given by intraperitoneal injection at doses previously determined to be of sufficient concentration to maintain depletion of specific cell subsets for the duration of the experiment (data not shown). An isotype-matched Ab (R35-38, rat immunoglobulin G2b, $\kappa$; PharMingen) was used as a negative control at 100 $\mu \mathrm{g} /$ mouse. Tumors were monitored as described above. 
A.

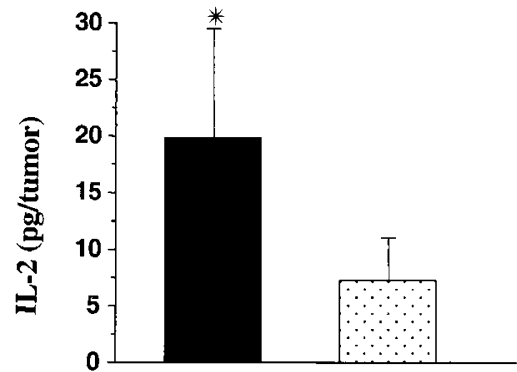

B.

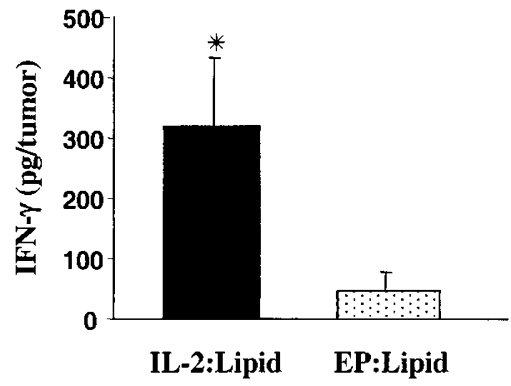

Figure 1. Cytokine production from cultured Renca tumor explants after IL-2:lipid treatment. BALB/c mice (six per group) were implanted s.c. in the flank with $7 \times 10^{5}$ Renca cells and treated 10 days later with $6 \mu \mathrm{g}$ of IL-2:lipid or EP:lipid. Tumors were harvested 24 hours after treatment and cultured for 24 hours. Culture media were assayed for IL-2 (A) and IFN- $\gamma$ (B) by ELISA. Data are presented as mean \pm SEM. $*, P<.05$.

\section{Combination of IL-2 gene therapy and chemotherapy}

Mice bearing Renca tumors were treated with $6 \mu \mathrm{g}$ of IL-2: lipid or EP:lipid twice per week for 2 weeks starting on day 7 after tumor challenge. After the first treatment, mice were also injected intravenously (i.v.) with $3 \times 10^{5}$ cells on day 9 after tumor challenge. Animals receiving 5-FU (Sigma, St. Louis, Mo) were dosed daily at $12 \mathrm{mg} / \mathrm{kg}$ (5 days per week for 2 weeks). Primary s.c. tumors were measured twice a week (see above). Animals with tumors of $>1 \mathrm{~cm}^{3}$ or animals who had lost $>20 \%$ of their body weight were sacrificed.

\section{Statistical analyses}

Tumor measurement data and cytokine ELISA data were analyzed using the nonparametric Mann-Whitney $U$ test. Tumor rejection data were analyzed using the $\chi^{2}$ test. In all cases, $P$ values of $<0.05$ were considered statistically significant.

\section{RESULTS}

Expression of IL-2 after i.t. injection of IL-2:lipid complexes

The expression of IL-2 within the tumor after IL-2:lipid treatment was analyzed. Mice were challenged s.c. with $7 \times 10^{5}$ Renca cells; ten days later, when tumor size was $\sim 20-25 \mathrm{~mm}^{3}, 6 \mu \mathrm{g}$ of IL-2:lipid or EP:lipid was injected i.t. Tumors were harvested 1 day later and cultured for 24 hours. The resulting conditioned medium was assayed for IL-2 by ELISA. Figure 1A shows that the IL-2 produced from tumors injected with IL-2:lipid was sig-

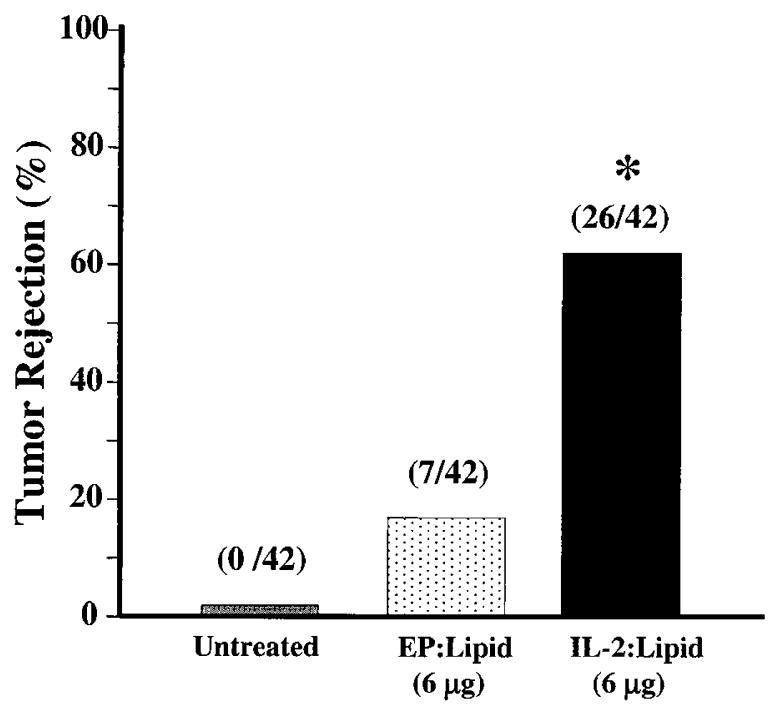

Figure 2. Antitumoral activity of IL-2 gene therapy. BALB/c mice were implanted s.c. with $7 \times 10^{5}$ Renca cells and treated 7 days later with EP:lipid or IL-2:lipid at 3- to 4-day intervals for 2 weeks (four treatments total). Groups of untreated tumor-bearing mice were also included. The percentage of total mice rejecting tumors in seven separate experiments is shown ( $n=6$ /group/experiment). The average percentage of rejection across all experiments was $62 \%$ (26 of 42 ) for IL-2:lipid, $17 \%$ (7 of 42 ) for EP:lipid, and $0 \%$ (0 of 42 ) for untreated mice. Rejection of established Renca tumors with IL-2:lipid compared with EP:lipid and untreated tumors was $P<$ .001 .

nificantly increased over the EP:lipid treatment. One of the characteristics of bacterial-derived DNA is to induce cellular immune responses in mammalian due to unmethylated $\mathrm{CpG}$ dinucleotide motifs contained within the DNA sequence. ${ }^{18,19}$ The generation of secondary cytokines, including IFN- $\gamma$, that promote a T helper type 1-dependent cell response, is observed in vivo after treatment with bacterial DNA. ${ }^{20}$ To determine whether there was a transgene-independent contribution of the DNA/lipid complex to the production of secondary cytokines, IFN- $\gamma$ was analyzed by ELISA. Figure 1B shows that the production of IFN- $\gamma$ by tumor explants was predominantly observed in mice treated with IL-2: lipid and not in the EP:lipid-treated group, suggesting an IL-2 transgene-dependent event.

\section{Antitumoral activity of IL-2:lipid treatment}

The antitumoral effect of IL-2:lipid was tested in vivo against established Renca tumors. Mice bearing $10-\mathrm{mm}^{3}$ tumors were treated i.t. with $6 \mu \mathrm{g}$ of IL-2:lipid or EP:lipid. Each group consisting of six or eight tumorbearing mice was treated at 3- to 4-day intervals (twice per week) for 2 weeks (four treatments total). Figure 2 shows the compiled result of seven independent experiments. A total of $62 \%$ of mice treated with IL-2:lipid (26 of 42) showed complete tumor rejection, whereas only a marginal tumor response $(17 \%)$ was observed in mice treated with EP:lipid (7 of 42). No untreated animal went into spontaneous tumor remission ( 0 of 42). 
Table 1. Antitumoral Response Generated by Local IL-2: Lipid Treatments

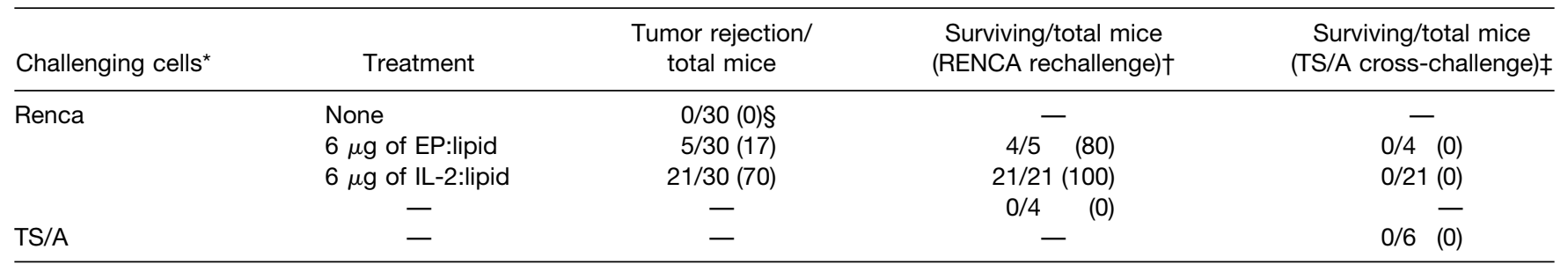

${ }^{*}$ Mice were challenged in the left flank with $7 \times 10^{5}$ Renca cells.

†Mice were rechallenged or challenged for the first time (control group) in the right flank with $1 \times 10^{6}$ Renca cells.

$\ddagger$ Mice were cross-challenged or challenged for the first time (control group) in the right flank with $2 \times 10^{5} \mathrm{TS} / \mathrm{A}$ cells.

§Numbers in parentheses indicate percentage of survival.

Inhibition of Renca tumor growth after IL-2:lipid treatment is associated with a systemic immune response

Mice that rejected primary Renca tumors after treatment with IL-2:lipid were rechallenged with a greater number of Renca cells $\left(1 \times 10^{6}\right)$ in the opposite flank from the initial tumor site at 42-62 days after initial tumor challenge. Naive animals were also challenged for the first time as a control group. All IL-2:lipid-treated mice (21 of 21 ) that rejected the primary tumor also rejected the Renca rechallenge. A total of $80 \%$ (four of five) of animals treated with EP:lipid were protected against tumor rechallenge (Table 1). To determine the tumor specificity of the immune response, surviving mice from the IL-2:lipid and EP:lipid treatment groups were cross-challenged 53 days after Renca rechallenge with a different syngeneic tumor line, TS/A. An inoculum of $2 \times 10^{5} \mathrm{TS} / \mathrm{A}$ cells was implanted into the opposite flank from the initial Renca challenge. A group of six naive animals was challenged as a control group. None of the IL-2:lipid-treated mice (0 of 21), EP:lipid-treated mice
( 0 of 4 ), or naive mice ( 0 of 6 ) rejected the TS/A cross-challenge (Table 1).

Antitumoral effects of IL-2:lipid in $\mathrm{CD}^{+}{ }^{+}, \mathrm{CD} 8^{+}-, \mathrm{NK}$-, or $P M N$-depleted mice To evaluate the contribution of various immune cells to the antitumoral response induced by IL-2:lipid, tumor-bearing mice were selectively immunosuppressed using anti-CD4, anti-CD8, antiPMN, or anti-NK Abs and then treated with IL-2:lipid. A depletion control group was treated with an irrelevant isotype-matched Ab before IL-2:lipid treatment. Depletion of $\mathrm{CD}^{+}$and NK cells abrogated the antitumoral effects of IL-2:lipid (Fig 3). PMN depletion also significantly disrupted the antitumoral response to the IL-2 gene therapy $(P=0.034)$, but to a lesser degree. Treatment with the control Ab did not have a significant effect on tumor rejection. Interestingly, $\mathrm{CD} 4^{+}$ depletion did not disrupt the antitumoral activity induced by IL-2:lipid, but, on the contrary, increased the number of tumor rejections from 11 of 16 mice with IL-2:lipid to 16 of 16 mice in the CD4 ${ }^{+}$-depleted group $(P=0.0515$, not significant $)$. The data suggest

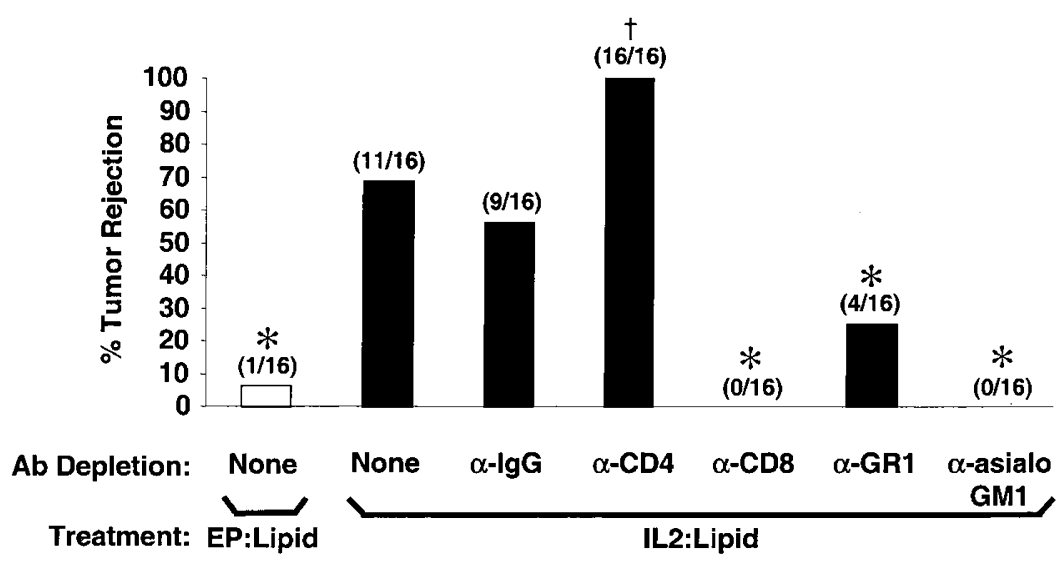

Figure 3. Tumor rejection in mice depleted of $\mathrm{CD}^{+}, \mathrm{CD}^{+}, \mathrm{NK}$, and PMN cells after IL-2:lipid treatment. The pooled data from two replicate experiments with 8 mice per group (16 mice per treatment) are shown. Renca cells $\left(7 \times 10^{5}\right)$ were implanted s.c. in the left flank of BALB/c mice on day 0 . Treatment with anti-CD4 ${ }^{+}$, anti-CD8 ${ }^{+}$, anti-GR1 ${ }^{+}(\mathrm{PMN})$, anti-asialo-GM1 ${ }^{+}(\mathrm{NK})$, or anti-immunoglobulin $\mathrm{G} 2 \mathrm{~b}, \kappa$ was performed on days 6 and 13 after tumor challenge (see Materials and Methods). Tumors were treated twice per week for 2 weeks with IL-2:lipid (6 $\mu \mathrm{g} /$ mouse/treatment) beginning 1 day after the initial depletion. The results are presented as the percentage of mice that rejected an established tumor. Numbers in parentheses represent the number of animals that rejected tumors out of the total number of mice per group. Tumor rejection was analyzed by $\chi^{2}$ analysis (*, $P<.05 ; \dagger, P=0.0515$, versus IL-2:lipid group). 


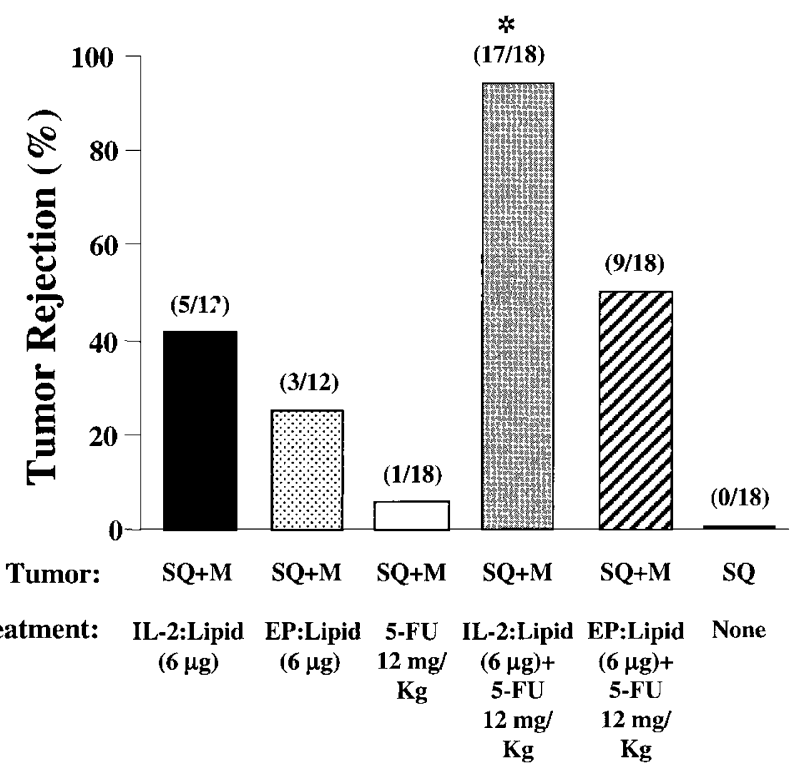

Figure 4. Combined antitumoral efficacy of IL-2 gene therapy and 5-FU. Tumor bearing-mice (s.c. $=\mathrm{SQ}$ ) receiving IL-2:lipid or EP:lipid (6 $\mu \mathrm{g} /$ mouse/treatment) were treated as described in Figure 2. At 2 days after the first treatment, mice were injected i.v. with $3 \times 10^{5}$ Renca cells ( $\mathrm{M}=$ metastases). Animals receiving 5 -FU were dosed daily at $12 \mathrm{mg} / \mathrm{kg}$ for 5 days per week for 2 weeks. Mice that rejected primary tumors also survived lung metastases. Numbers in parentheses represent the number of animals that rejected tumors out of the total number of mice per group. $*, P<.05$ versus the IL-2:lipid and EP:lipid plus 5-FU groups.

a suppressive effect of at least some subset of $\mathrm{CD} 4^{+}$ cells on antitumoral activity.

\section{Combination of IL-2 gene therapy with 5-FU}

We investigated whether the antitumoral activity induced by IL-2:lipid treatments could be increased by systemic administration of a conventional chemotherapeutic agent, 5-FU, in mice bearing primary tumor and lung metastases. Mice received primary tumor (s.c.) challenge followed by IL-2:lipid treatment 7 days later, when tumors were $\sim 10 \mathrm{~mm}^{3}$. At 2 days after the first IL-2:lipid treatment, mice were also challenged i.v. with $3 \times 10^{5}$ Renca cells to induce lung metastases. Figure 4 shows tumor rejection as result of combining 5-FU treatment with IL-2 gene therapy. Mice that rejected primary tumors also survived lung metastases. A total of $42 \%$ of the mice treated with IL-2:lipid rejected their primary tumor (5 of 12) compared with $94 \%$ (17 of 18) of the mice receiving IL-2:lipid and 5-FU, suggesting an additive effect of gene therapy with 5-FU. The tumor rejection observed for the IL-2:lipid plus 5-FU groups was statistically different from either the IL-2:lipid or EP:lipid plus 5-FU groups.

\section{DISCUSSION}

In this study, we present evidence that delivery of IL-2 gene to established tumors by a nonviral vector system induces a potent antitumoral response primarily mediated by $\mathrm{CD}^{+} \mathrm{T}$ lymphocytes, granulocytes, and $\mathrm{NK}$ cells. Combination of IL-2 gene therapy with 5-FU treatment increases the antitumoral efficacy and survival of mice bearing primary and metastatic tumors.

Cytokines naturally work in a paracrine fashion within a local microenvironment. Systemic administration of cytokines for cancer immunotherapy produces high concentrations of these proteins at sites distant from the antigen and often suboptimal levels in the tissues of interest. ${ }^{21}$ Continuous IL-2 production induced by local gene therapy will minimize IL-2 toxicity, overcome the problem of a short half-life, and produce IL-2 at the site of interest, inducing a local immune response. Direct viral IL-2 gene delivery studies mediated by adenovirus, ${ }^{10-11}$ retrovirus, ${ }^{22}$ and vaccinia virus ${ }^{23}$ have shown antitumoral efficacy in mouse models of primary cancer. However, concerns about viral replication and integration with viral vectors, along with additional manufacturing challenges, make these methods less attractive for widespread gene therapy.

By using a novel lipid delivery system to treat primary and metastatic tumors with the IL-2 gene, we first demonstrated detectable IL-2 production within the tumor after injection of IL-2:lipid complexes (Fig 1A). The detection of IL-2 produced from cultured mouse tumors may likely be underestimated due to trapping of cytokine within the tumor mass, receptor-mediated uptake by activated leukocytes, enzymatic degradation, and death of transfected producer cells during culture. IFN- $\gamma$ was also detected in mice treated with IL-2:lipid and not in the EP:lipid-treated group, suggesting a direct IL-2 transgene event and its potential contribution to the overall antitumoral response induced by IL-2:lipid treatment. It is unlikely that the differences observed in IFN- $\gamma$ induction were due to differences in contaminating levels of endotoxin in the plasmid preparations, because the EP DNA actually had slightly higher levels of endotoxin than the IL-2 DNA.

The $62 \%$ average rejection of Renca tumors with a $6-\mu \mathrm{g}$ dose of IL-2:lipid versus only $17 \%$ tumor rejection with the same dose of EP:lipid demonstrates a specific effect of the IL-2 transgene. Parker et al ${ }^{15}$ used 1,2dimyristyloxypropyl- $N, N$-dimethyl- $N$-hydroxyethylammonium bromide/dioleoylphosphatidylethanolamine (50- $\mu$ g DNA dose, 5:1 DNA:lipid mass ratio) to transfect s.c. B16 melanoma tumors in vivo; however, they were not able to demonstrate a specific IL-2 effect, because both a control plasmid and an IL-2 plasmid slowed tumor growth. The nonspecific effect was DNA dose-dependent, and they suggested that the nonspecific effects could be overcome with higher IL-2 expression. Our experience suggests that lower DNA/lipid doses balance transgene expression, with minimization of nonspecific cytokine induction (data not shown). Animals that rejected an initial Renca challenge after IL-2:lipid treatment were rechallenged in the opposite flank with a higher cell inoculum. Treatment with IL-2 plasmid gave strong memory against rechallenge, with $100 \%$ (21 of 21) of the animals rejecting the rechallenge (Table 1). 
To test the specificity of the antitumoral immune memory induced in our system, animals surviving rechallenge for $>50$ days were cross-challenged with an unrelated syngeneic tumor cell implant. None of the animals were able to reject the cross-challenge, indicating that the immunological memory was indeed Renca-specific (Table 1). Animals that rejected tumors after EP:lipid treatment were also resistant to Renca rechallenge (80\% survival) but not to cross-challenge. This indicates that although IL-2 production strongly induces tumor rejection that is associated with specific immune memory, such immunity could also be generated by EP:lipid treatment.

To assess the role of the effector cells involved in the immune response, animals were depleted of $\mathrm{CD}^{+}$, $\mathrm{CD}^{+}, \mathrm{NK}$, or PMN cells before IL-2:lipid treatment. We showed that $\mathrm{CD}^{+}$, NK, and PMN cells were necessary for antitumoral effects in our Renca model (Fig 3). Studies with IL-2-secreting TS/A tumors have shown previously that depleting $\mathrm{CD} 8^{+}$cells and granulocytes diminished the antitumoral response, whereas immunosuppression of $\mathrm{NK}$ and $\mathrm{CD} 4^{+}$cells had little effect. $^{5,23-25}$ In our model, $\mathrm{CD} 4^{+}$depletion increased tumor rejection, indicating that some subpopulation of $\mathrm{CD}^{+}$cells may suppress antitumoral activity. Similar $\mathrm{CD}^{+}{ }^{+}$suppression of antitumoral effects has been observed with systemic rIL-2 treatment in a murine model of advanced sarcoma. ${ }^{26}$

Immunotherapy with rIL-2 has been shown to enhance the antitumoral activity of chemotherapeutic drugs in a variety of combinations in clinical studies. ${ }^{27-33}$ In a study of patients with metastatic colorectal cancer treated with IL-2 and 5-FU, $28 \%$ of patients showed $>50 \%$ regression in the size of their tumors and $43 \%$ had stable disease over the course of the study. ${ }^{33}$ These data suggest that the IL-2 and 5-FU combination therapy has promise, and that IL-2 gene therapy could be employed to give the benefits of IL-2 without the adverse effects associated with the systemic administration of this cytokine. In the absence of the toxic side effects of systemic IL-2, local production of IL-2 combined with 5-FU may be even more effective. We examined the effects of the combination of local IL-2 gene therapy and systemic 5-FU in mice bearing an established primary tumor and lung metastases. This model mimics clinical cases in which patients display primary tumors associated with established or undetected metastases. The $12-\mathrm{mg} / \mathrm{kg}$ dose of $5-\mathrm{FU}$ used in these experiments was well tolerated in the mice and gave increased efficacy without immunosuppression. Our hypothesis is that the antimetabolite, 5-FU, acts to slow the growth of the tumors long enough to give the immune system a larger therapeutic window in which to work. Interestingly, the $42 \%$ of animals that rejected established primary flank tumors after IL-2:lipid treatment (Fig 4) also did not develop lung metastases. This is another indicator of the robustness of the IL-2:lipid response. The $94 \%$ of animals treated with IL-2:lipid and 5-FU that rejected the primary tumor also survived the lung metastases.
In this study, we present evidence that delivery of the IL-2 gene to established tumors by a nonviral vector system induces a potent antitumoral response primarily mediated by $\mathrm{CD}^{+} \mathrm{T}$ cells, granulocytes, and NK cells. We have also shown that a conventional chemotherapeutic agent, 5-FU, can be used in combination with IL-2 gene therapy to enhance the antitumoral activity. These data suggest that cytokine gene therapy may have a role as adjunct therapy to existing chemotherapeutic regimes. Clinical trials using a slightly modified human IL-2 plasmid formulated in DOTMA:cholesterol are currently underway. ${ }^{34}$

\section{ACKNOWLEDGMENTS}

We thank Dr. Michael Fons for helpful discussions and critical review of the manuscript and the Integrated Manufacture and Analytics teams at Valentis, Inc. for supplying the plasmids. We also thank the Laboratory Animal Resource staff for animal care.

\section{REFERENCES}

1. Mulders P, Figlin R, deKernion JB, et al. Renal cell carcinoma: recent progress and future directions. Cancer Res. 1997;57:5189-5195.

2. Kragel AH, Travis WD, Feinberg L, et al. Pathologic findings associated with interleukin-2-based immunotherapy for cancer: a postmortem study of 19 patients. Hum Pathol. 1990;21:493-502.

3. Fleischmann JD, Shingleton WB, Gallagher C, Ratnoff OD, Chahine A. Fibrinolysis, thrombocytopenia, and coagulation abnormalities complicating high-dose interleukin-2 immunotherapy. J Lab Clin Med. 1991;117:76-82.

4. Baars JW, Hack CE, Wagstaff J, et al. The activation of polymorphonuclear neutrophils and the complement system during immunotherapy with recombinant interleukin-2. Br J Cancer. 1992;65:96-101.

5. Fearon E, Pardoll D, Itaya T, et al. Interleukin-2 production by tumor cells bypasses $\mathrm{T}$ helper function in the generation of an anti-tumor response. Cell. 1990;60:397-403.

6. Gansbacher B, Zeir K, Daniels B, Cronin K, Bannerji R, Gilboa E. Interleukin-2 gene transfer into tumor cells abrogates tumorigenicity and induces protective immunity. J Exp Med. 1990;172:1217-1224.

7. Shawler DL, Dorigo O, Gjerset RA, Royston I, Sobol RE, Fakhrai H. Comparison of gene therapy with interleukin-2 gene-modified fibroblasts and tumor cells in the murine CT-26 model of colorectal carcinoma. J Immunother. 1995; 17:201-208.

8. Fakhrai H, Shawler DL, Gjerset R, et al. Cytokine gene therapy with interleukin-2-transduced fibroblasts: effects of IL-2 dose on anti-tumor immunity. Hum Gene Ther. 1995;6:591-601.

9. Tepper RI, Mule JJ. Experimental and clinical studies of cytokine gene-modified tumor cells. Hum Gene Ther. 1994;5:153-164.

10. Toloza EM, Hunt K, Swisher S, et al. In vivo cancer gene therapy with a recombinant interleukin-2 adenovirus vector. Cancer Gene Ther. 1996;3:11-17.

11. Addison CL, Braciak T, Ralston R, Muller WJ, Gauldie J, Graham FL. Intratumoral injection of an adenovirus ex- 
pressing interleukin 2 induces regression and immunity in a murine breast cancer model. Proc Natl Acad Sci USA. 1995;92:8522-8526.

12. Rakhmilevich RL, Janssen K, Turner J, Culp J, Yang NS. Cytokine gene therapy of cancer using gene gun technology: superior anti-tumor activity of interleukin-12. Hum Gene Ther. 1997;8:1303-1311.

13. Sun WH, Burkholder JK, Sun J, et al. In vivo cytokine gene transfer by gene gun reduces tumor growth in mice. Proc Natl Acad Sci USA. 1995;92:2889-2893.

14. Saffran DC, Horton HM, Yankauckas MA, et al. Immunotherapy of established tumors in mice by intratumoral injection of interleukin-2 plasmid DNA: induction of $\mathrm{CD}^{+}$T-cell immunity. Cancer Gene Ther. 1998;5:321-330.

15. Parker SE, Khatibi S, Margalith M, et al. Plasmid DNA gene therapy: studies with the human interleukin-2 gene in tumor cells in vitro and in the B16 melanoma model in vivo. Cancer Gene Ther. 1996;3:175-185.

16. Nanni P, De Giovanni C, Lollini PL, Nicoletti G, Prodi G. TS/A: a new metastasizing cell line originated from BALB/c spontaneous mammary adenocarcinoma. Clin Exp Metastasis. 1983;1:373-380.

17. Chen SH, Chen XH, Wang Y, Kosai K, Finegold MJ, Rich SS, Woo SL. Combination gene therapy for liver metastases of colon cancer in vivo. Proc Natl Acad Sci USA. 1995;92:2577-2581.

18. Krieg AM, Yi AK, Matson S, et al. CpG motifs in bacterial DNA trigger direct B-cell activation. Nature. 1995;374: $546-549$.

19. Klinman DM, Yi AK, Beaucage SL, Conover J, Krieg AM. $\mathrm{CpG}$ motifs present in bacteria DNA rapidly induce lymphocytes to secrete interleukin 6, interleukin 12, and interferon $\gamma$. Proc Natl Acad Sci USA. 1996;93:2879-2883.

20. Freimark BD, Blezinger HP, Florack VJ, et al. Cationic lipids enhance cytokine and cell influx levels in the lung following administration of plasmid:cationic lipid complexes. J Immunol. 1998;160:4580-4586.

21. Pardoll DM. Paracrine cytokine adjuvants in cancer immunotherapy. Annu Rev Immunol. 1995;13:399-415.

22. Gunji Y, Tasaki K, Tagawa M, et al. Inhibition of peritoneal dissemination of murine colon carcinoma cells by administrating retrovirus harboring IL-2 gene. Cancer Gene Ther. 1998;5:339-343.

23. Acres B, Dott K, Stefani L, Kieny MP. Directed cytokine expression in tumour cells in vivo using recombinant vaccinia virus. Ther Immunol. 1994;1:17-23.
24. Cavallo F, Giovarelli M, Gulino A, et al. Role of neutrophils and $\mathrm{CD}^{+} \mathrm{T}$ lymphocytes in the primary and memory response to a nonimmunogenic murine mammary adenocarcinoma made immunogenic by IL-2 gene. $J$ Immunol. 1992;149:3627-3635.

25. Musiani P, Modesti A, Giovarelli M, et al. Cytokines, tumour cell death, and immunogenicity: a question of choice. Immunol Today. 1997;18:32-36.

26. Rakhmilevich AL, North RJ. Elimination of $\mathrm{CD}^{+}{ }^{+} \mathrm{T}$ cells in mice bearing an advanced sarcoma augments the antitumor action of interleukin-2. Cancer Immunol Immunother. 1994;38:107-112.

27. Sella A, Kilbourn RG, Gray I, et al. Phase I study of interleukin-2 combined with interferon- $\alpha$ and 5-fluorouracil in patients with metastatic renal cell cancer. Cancer Biother. 1994;9:103-111.

28. Flaherty LE, Robinson W, Redman BG, et al. A phase II study of dacarbazine and cisplatin in combination with outpatient-administered interleukin-2 in metastatic malignant melanoma. Cancer. 1993;71:3520-3525.

29. Paciucci PA, Bekesi JG, Ryder JS, Odchimar R, Chahinian PA, Holland JF. Immunotherapy with IL-2 by constant infusion and weekly doxorubicin. Am J Clin Oncol. 1991; $14: 341-348$

30. Okuno K, Hirohata T, Nakamura K, et al. Hepatic arterial infusions of interleukin-2-based immunochemotherapy in the treatment of unresectable liver metastases from colorectal cancer. Clin Ther. 1993;15:672-683.

31. Valone FH, Gandara DR, Deisseroth AB, et al. Interleukin-2, cisplatin, and 5-fluorouracil for patients with nonsmall cell lung and head/neck carcinomas. J Immunother. 1991;10:207-213.

32. Lopez-Hanninen E, Kirchner H, Atzpodien J. Interleukin2-based home therapy of metastatic renal cell carcinoma: risks and benefits in 215 consecutive single institution patients. J Urol. 1996;155:19-25.

33. Hamblin TJ, Inzani V, Sadullah S, et al. A phase II trial of recombinant interleukin-2 and 5-FU chemotherapy in patients with metastatic colorectal carcinoma. Cancer Treat Rev. 1989;16(Suppl A):163-167.

34. Wollenberg B, Kastenbauer, Mundl H, et al. Gene therapy: phase I trial for primary untreated head and neck squamous cell cancer (HNSCC) UICC stage II-IV with a single intratumoral injection of hIL-2 plasmids formulated in DOTMA/Chol. Hum Gene Ther. 1999;10:141-147. 